\title{
Subcloning of NGF Gene into pSecTag2/Hygro Secretory Vector and Expression in PC12 Cell Line
}

\author{
Bahman Jalali Kondori $^{* *}$, Mohammad Hossein Asadi' ${ }^{1}$ Fateme Azemati $^{2}$ \\ ${ }^{1}$ Department of Anatomical Sciences, School of Medicine, Baqiyatallah University of Medical Sciences, Tehran, Iran. \\ ${ }^{2}$ Department of Biology, School of Basic Sciences, Science and Research Branch, Islamic Azad University, Tehran, Iran.
}

\section{A BSTRACT}

Introduction: Subcloning of specific genes in plasmids and transfecting them into target cells for producing therapeutic proteins or cell differentiation, is suggested as one of the most effective treatment methods for different diseases. Nerve growth factor (NGF) is one of the members of the neurotrophin family. Neurotrophins are a family of proteins that regulate the survival, differentiation, and function of different types of neurons. Studies showed that NGF gene expression in stem cells induces differentiation toward neuron-like cells as well as the growth of axons and its branching. Materials and Methods: In this research, enzymatic digestion on a plasmid carrying NGF gene was performed and extracted. NGF gene was subcloned into pSecTag2/Hygro secretory plasmid. The subcloned plasmid was precipitated and concentrated. It was then transfected by Lipofectamine into PC12 cell line. NGF gene expression and protein production were evaluated using RT-PCR and western blot methods. Results: Sequence determination indicated that secretory plasmid subcloning process has been correct. Expression of NGF gene in transfected PC12 cells was shown by RT-PCR method and production of its protein was proved by the results from western blots.

Conclusion: Subcloning of NGF gene in pSecTag2 secretory vector is a suitable technique for transfer to eukaryotic cells.

\section{Key words:}

1. Transfection

2. Genetic Vectors

3. Nerve Growth Factors

4. PC12 Cells

* Corresponding Author: Bahman Jalali Kondori

E-mail: Bahmanjalali2010@gmail.com 


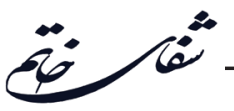

\section{ساب كلونينَ زن NGF در وكتورترشحى pSecTag2/Hygro و بيان آن در سلولهاى رده PC12}

$$
\text { بهمن جلالى كندرى ":"، محمد حسين اسدى'، فاطمه عظمتى ' }
$$

كَروه علوم تشريح، دانشكده يزشكى، دانشكاه علوم يزشكى بقيه الله، تهران، ايران.

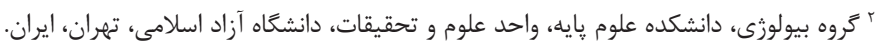

كليد وازهها:

ا

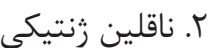

r.

PC12 r.



مقدمه: ساب كلونينَ زن هاى اختصاصى در يلاسميدها و انتقال آنها به سلولهاى هدف به منظور توليد

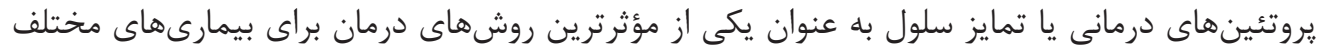

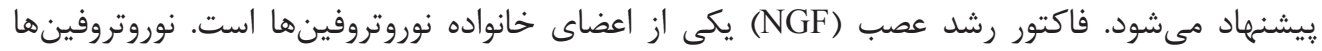



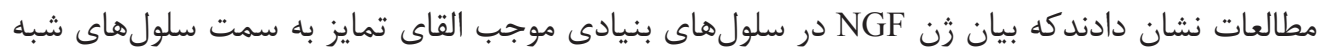

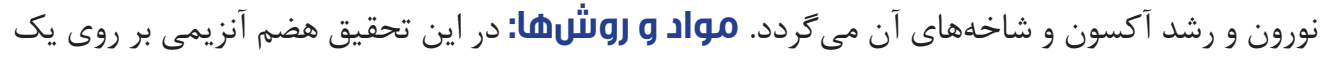

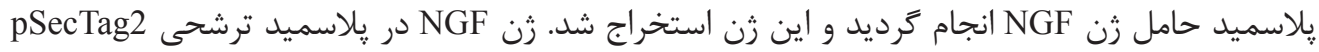

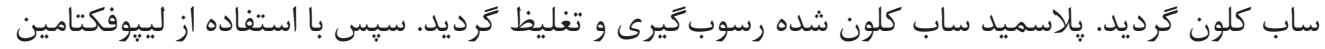

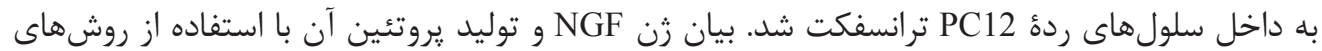

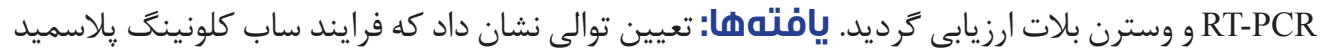

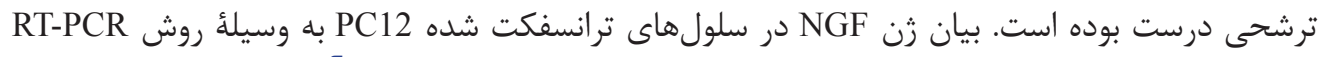

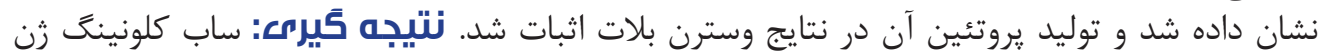

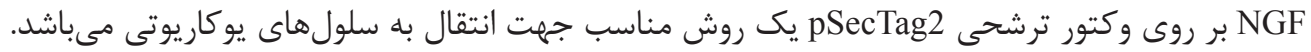

" نويسنده مسئول: بهمن جلالى كندرى "

آدرس الكترونيكى: Bahmanjalali2010@gmail.com 
حاصل از بيان زن، به دليل دارا بودن سيخنال يِيتيد

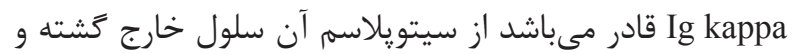

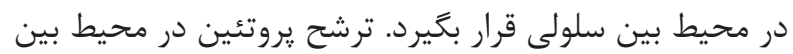

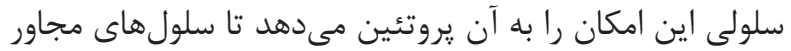

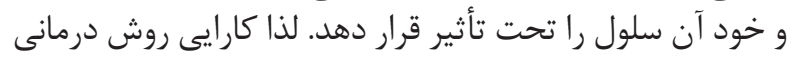

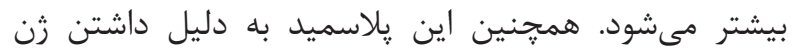

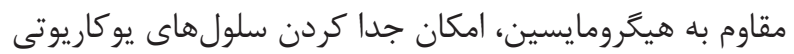

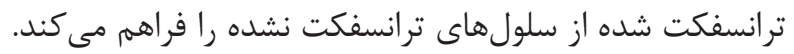

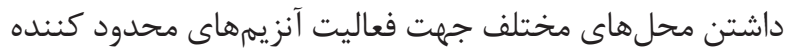
از ديگر مزاياى اين هيلاسميد ترشحى مى باشد.

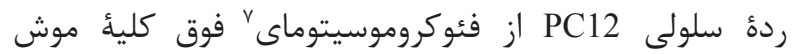

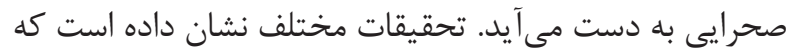

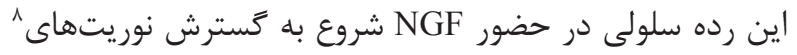

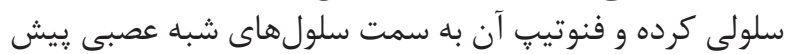



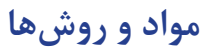

ترانسفورم و تكثير هلاسميدها

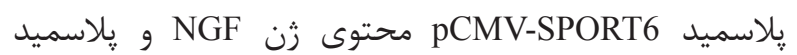

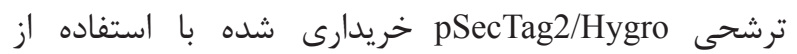

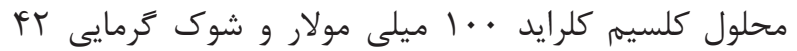

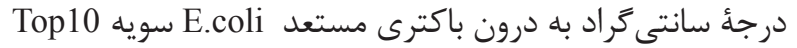

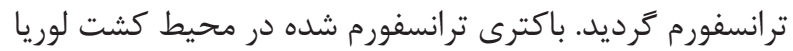

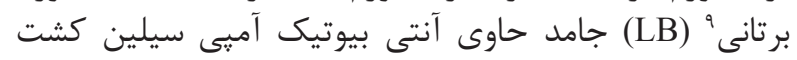

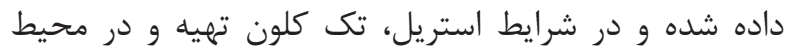

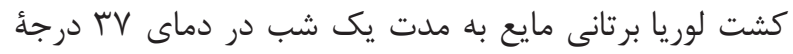

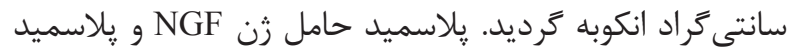

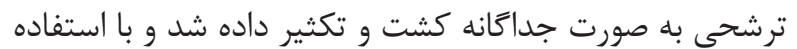

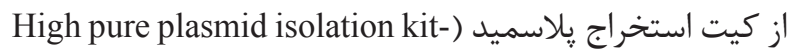

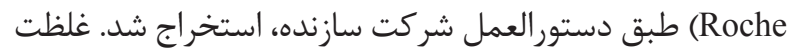

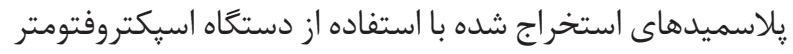

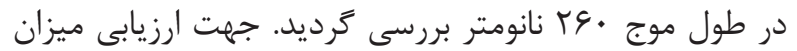

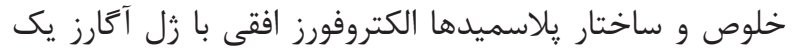

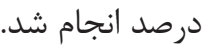

\section{ساب كلونينََ زن NGF در پِلاسميد ترشحى}

يلاسميد pCMV-SPORT6 (Invitrogen) و קِلاسميد ترشحى pSecTag2 (Invitrogen) Xho1 (Fermentas) و به طور جداكانه (Fermentas)

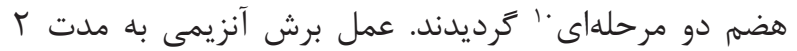



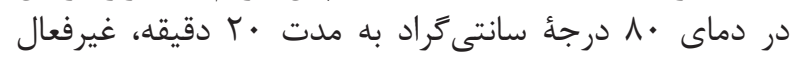



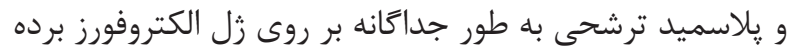

${ }^{1}$ Lipofection

${ }^{2}$ Microinjection

${ }^{3}$ Electroporation

${ }^{4}$ Brain-derived neurotrophic factor

${ }^{5}$ Nerve growth factor

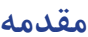

رن درمانى يكى از روشهاى با ارزش در درمان بيمارىها و توليد

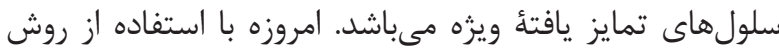

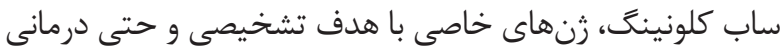

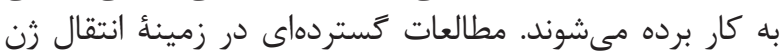

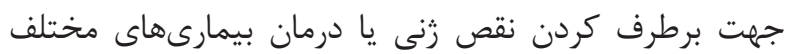

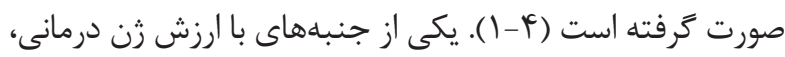

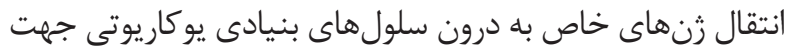

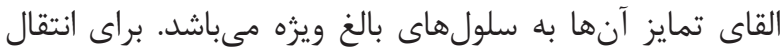

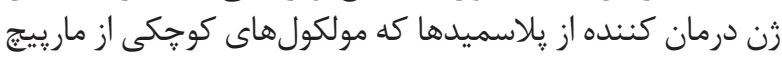
دولايه DNA مى دياشند، استفاده مىشود.

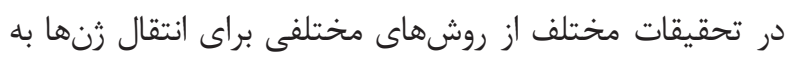

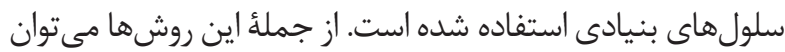

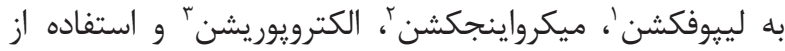

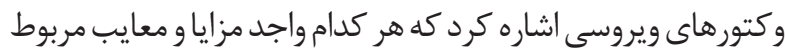

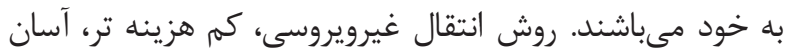

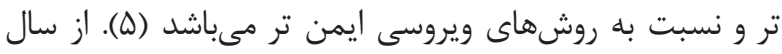

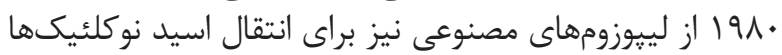

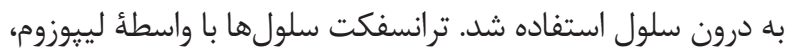

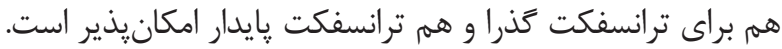

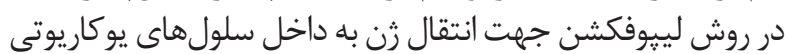

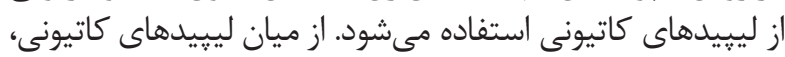

لييوفكتامين بيشترين بازده انتقال را دارد (9).

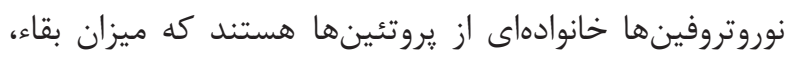

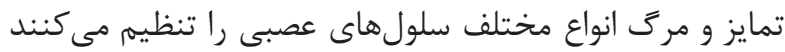

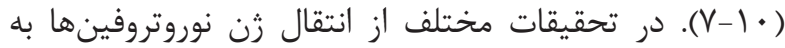

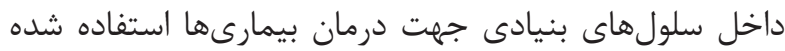

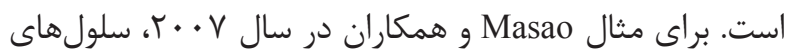

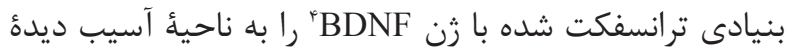

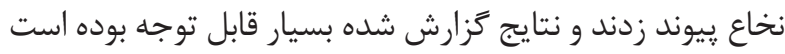

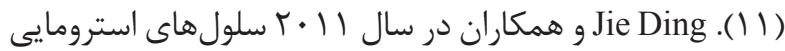

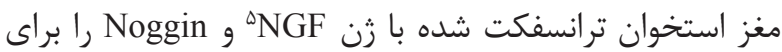

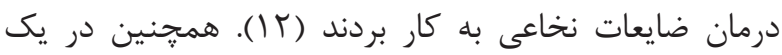

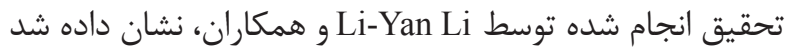

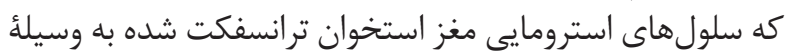

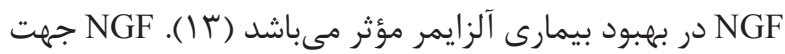

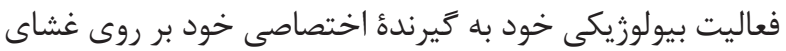

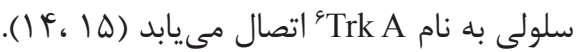

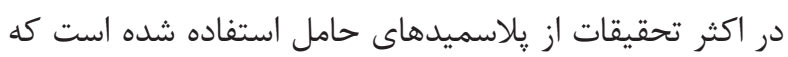

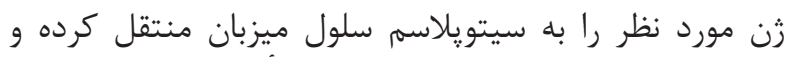

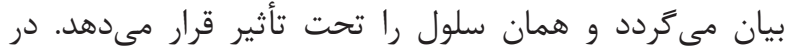


كرديد. زمانى كه از يلاسميد ترشحى استفاده مي شوشود، يروتئين

\footnotetext{
${ }^{6}$ Tyrosine kinase receptor

${ }^{7}$ Pheochromocytoma

${ }^{8}$ Neurites

${ }^{9}$ Luria Bertani

${ }^{10}$ Double digest
} 
ميكروتيوب حاوى لييوفكتامين بر روى ميكروتيوب ديخر اضافه

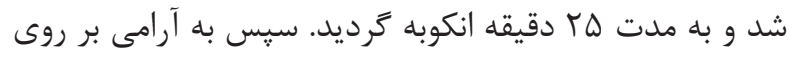

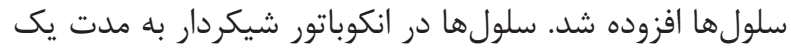

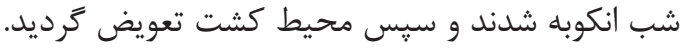
استخراج RNA، سنتز cDNA و واكنش زنجيرهاى یليمراز

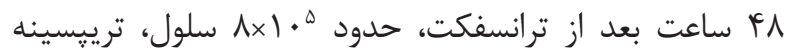


كNA (Isolation Kit-Roche

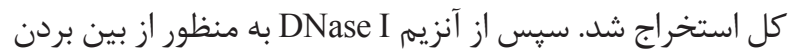
و افزايش خلوص RNA به mRNA سلولهاى ترانسفكت شده به وسيلئ آنزيم Reverse Transcriptase

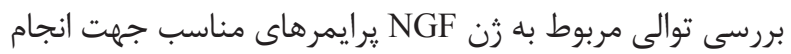
RT-PCR

F-Primer: 5'-CAACAGGACTCACAGGAGCA-3' R-Primer: 5'-GTCTGTGGCGGTGGTCTTAT-3'

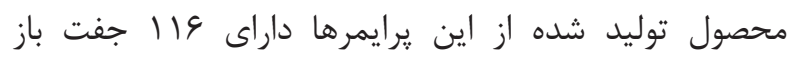

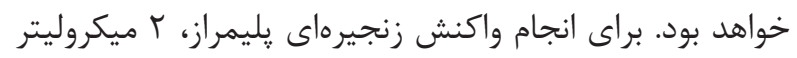

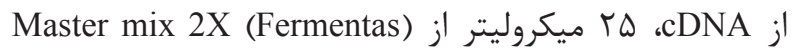

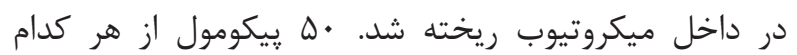

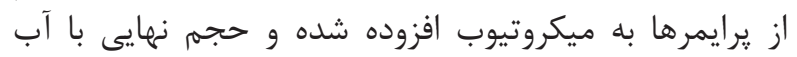
Nuclease free

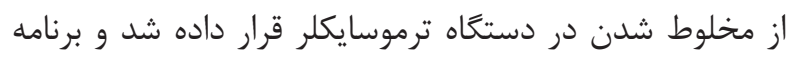
مناسب طبق جدول ا تعريف گرديد.

SDS-PAGE

جهت بررسى سنتز يروتئين NGF در سلولهاى ترانسفكت

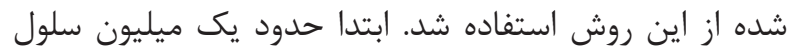



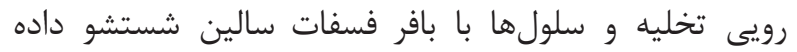

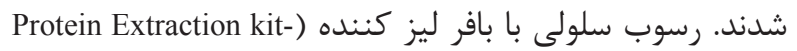
(ProteoJETTM Membrane Fermentas

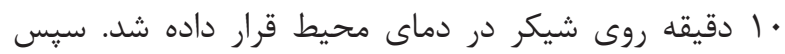

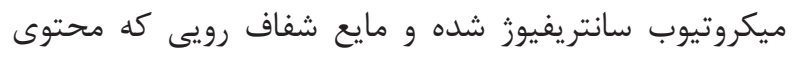

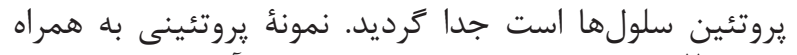

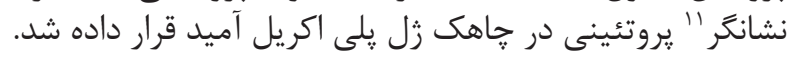

شدند و صحت برش آنزيمى بررسى گرديد.

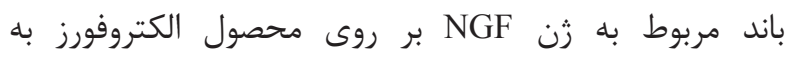


Extraction Kit- Fermentas هSecTag2

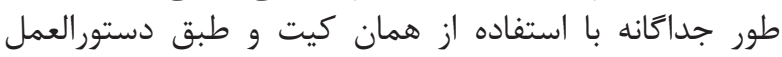

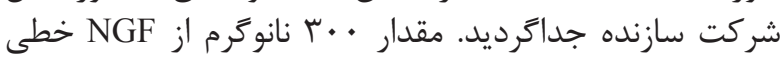

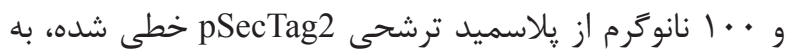

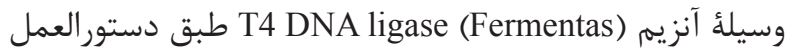

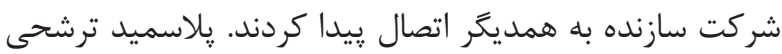
plecTag2 باكترى به مدت يك شب در انكوباتور كشت داده شد. يلاسميد

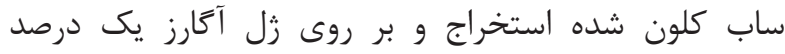

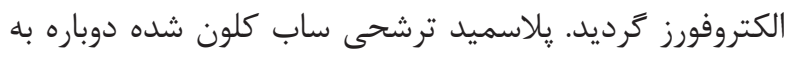

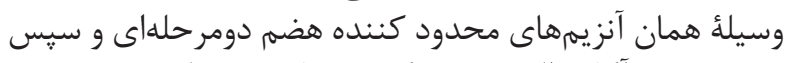

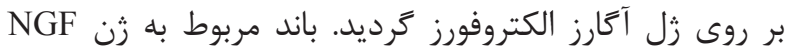

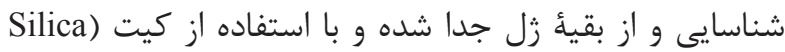
شن Bead DNA Gel Extraction Kit- Fermentas

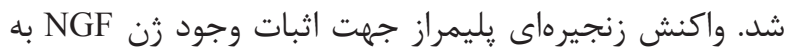

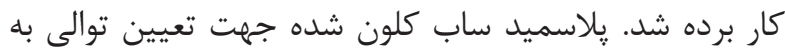

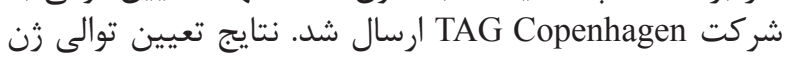
NGF زنى در سايت www.ncbi.nlm.nih.gov/blast بلاست زرديد. تر انسفكت سلول هاى PC12 با يلاسميد ساب كلون شده در ادامه جهت بررسى بيان زن در سلولهاى داى يوكاريوتى،

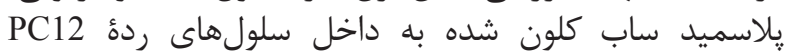

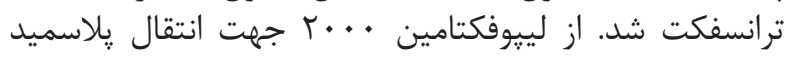



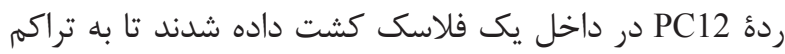

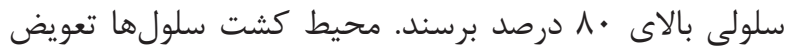

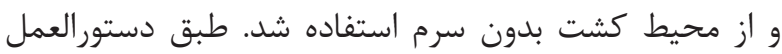

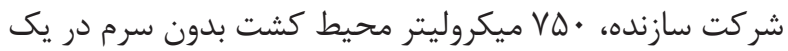

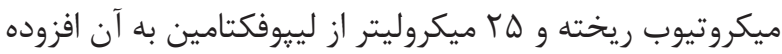

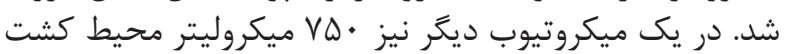

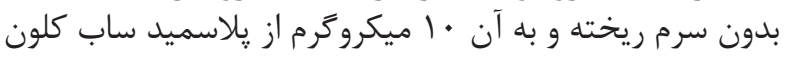

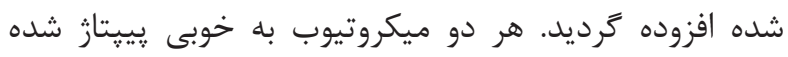

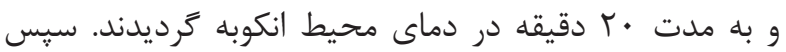

جدول ا- مراحل انجام واكنش زنجيرهاى يليمراز در دستكاه ترموسايكلر.

\begin{tabular}{|c|c|c|c|}
\hline تعداد سيكل & زمان & دما & مر حله \\
\hline 1 & ه دقيقه & $94^{\circ} \mathrm{C}$ & Initial Denaturation \\
\hline \multirow{3}{*}{ ro } & dأ ثانيه & $90^{\circ} \mathrm{C}$ & Denaturation \\
\hline & هأ ثانيه & $4 \cdot{ }^{\circ} \mathrm{C}$ & Annealing \\
\hline & ها ثانيد & $V r^{\circ} \mathrm{C}$ & Extension \\
\hline 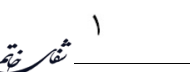 & ه دقيقه & $V r^{\circ} \mathrm{C}$ & Final Extension \\
\hline
\end{tabular}

${ }^{11}$ Marker 
مشاهده مىشود. اين باند نشانگر زن NGF مى مقاشد كه در اثر

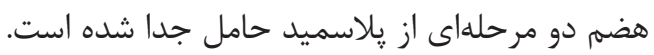

همانطور كه در تصوير r ديده مىشود وزن بِاسميد ساب كلون



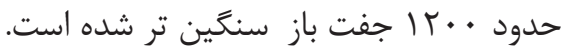
هضم آنزيمى مجدد بر روى پيلاسميد ساب كلون شده، انجام

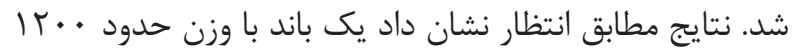

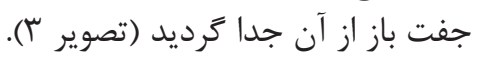
نتايج بلاست توالى زن NGF در بانك زنى در در دايت 99 www.ncbi.nlm.nih.gov/blast درصدى توالى بود. اين نتايج درستى فرايند ساب كلونينَ زن رنّان

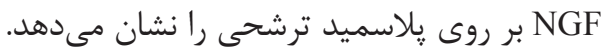
نتايج RT-PCR نشان مىدهد زن NGF ساب كلون شده در

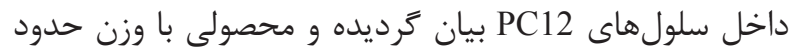

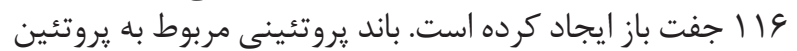
NGF

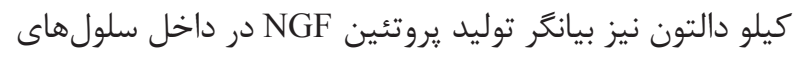

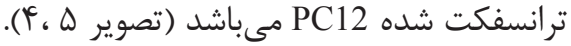

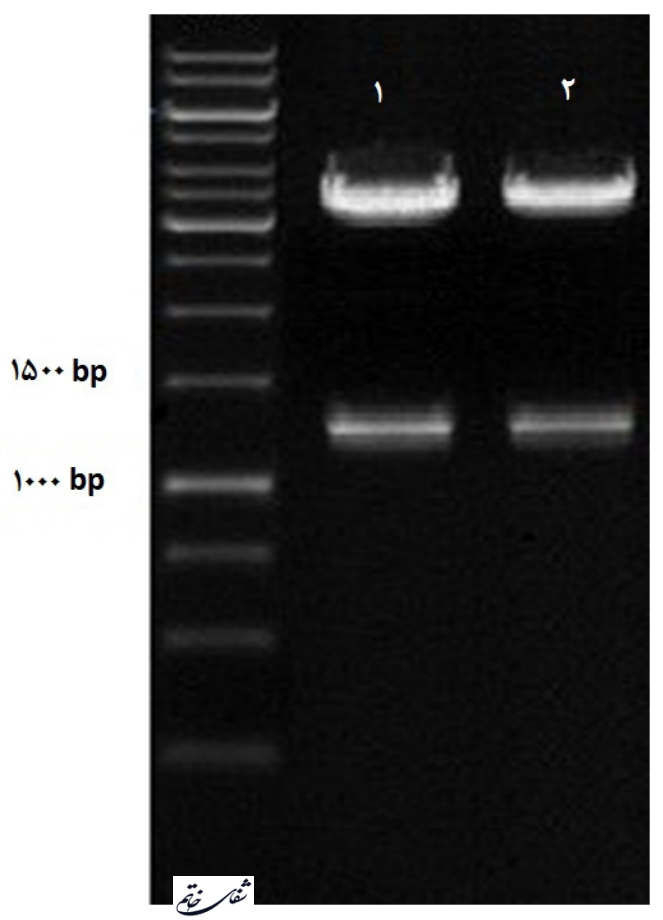

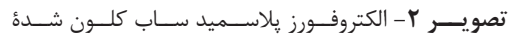



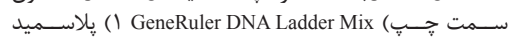
pSecTag2/Hygro

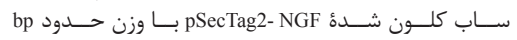

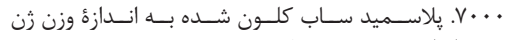

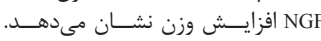

در اين تحقيق از زل جداكننده با درصد و زل متراكم كننده

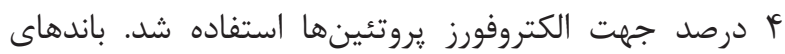

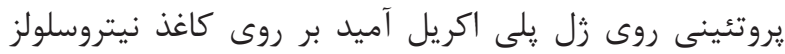

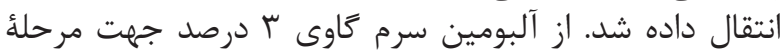

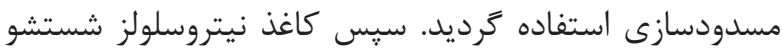

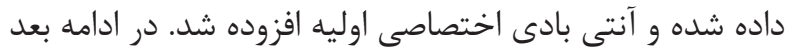

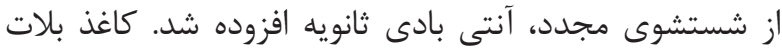

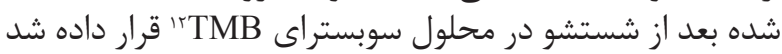



بافتهها

نتايج الكتروفورز گيلاسميدهاى استخراج شده نشان داد فرايند

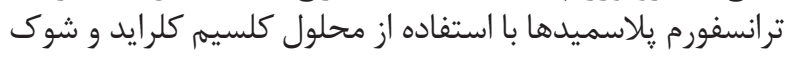

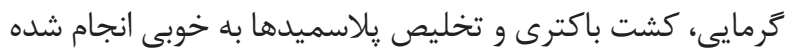

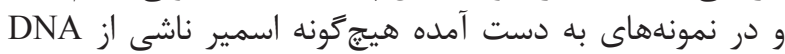

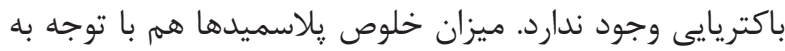
نسبت جذب A260/280 برابر با /1/ و و در حد حد استاندارد بود.

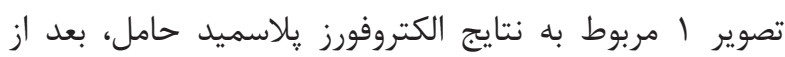

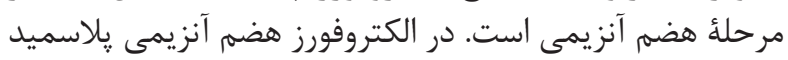

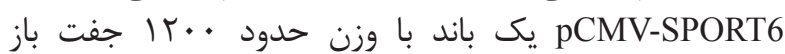

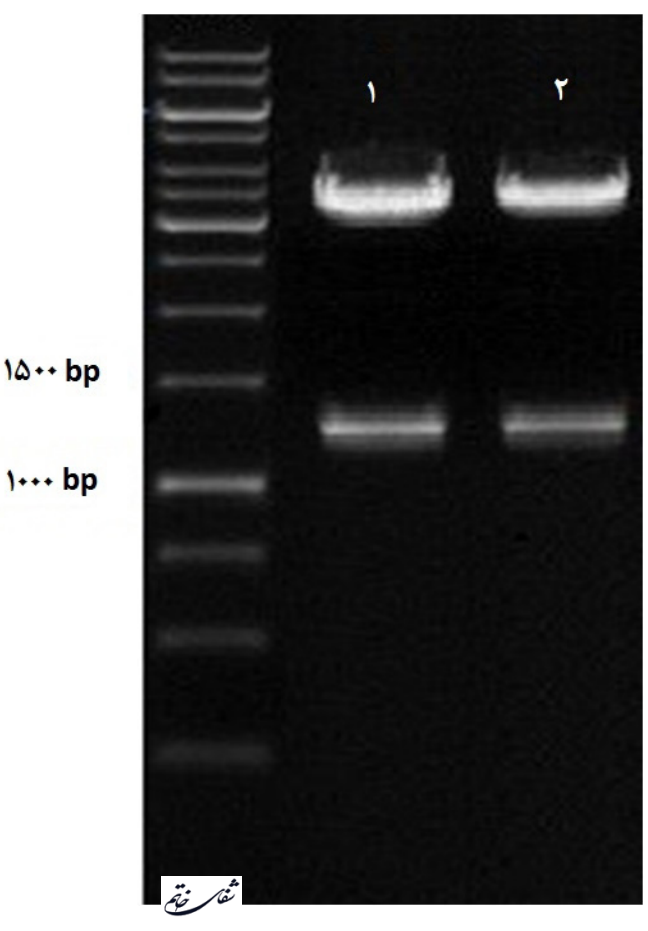

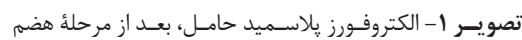

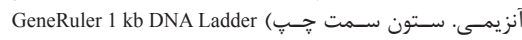

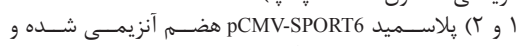

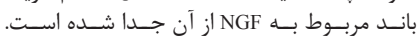

${ }^{12}$ Tetramethylbenzidine

${ }^{13}$ Immunoblotting 


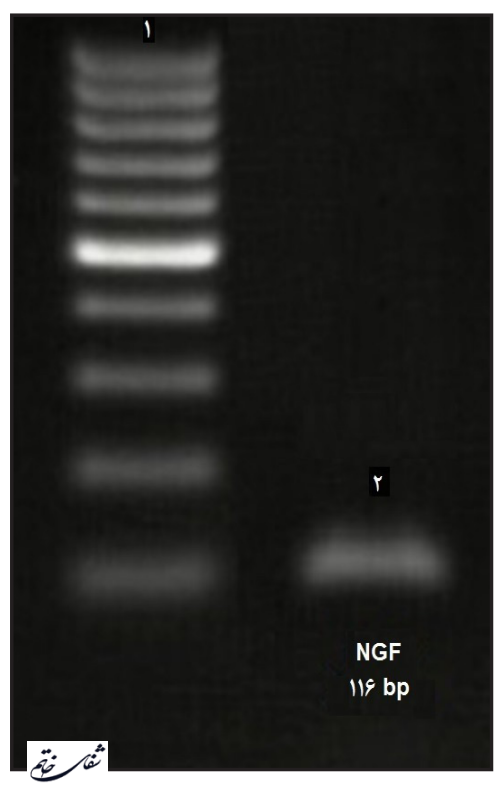

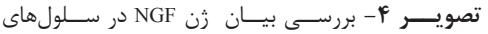

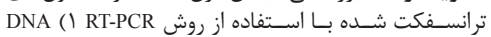

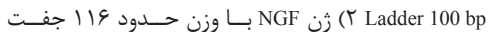

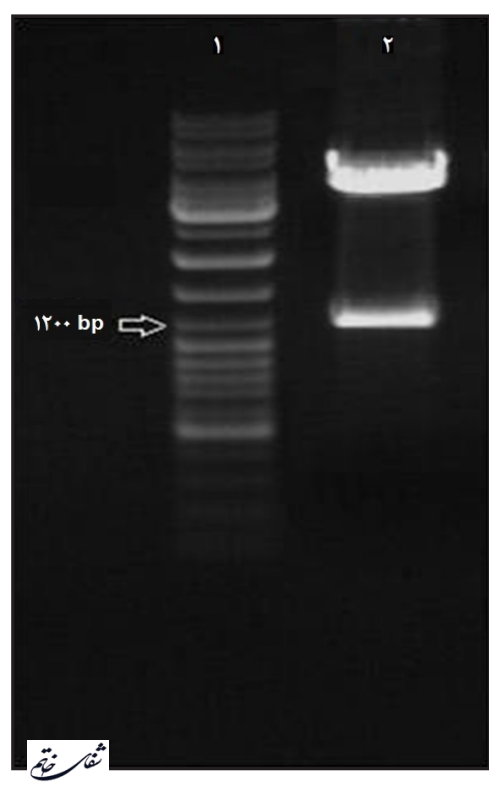

تصويــر بـ الكتروفـورز هضـم آنزيمسى يلاسـميد سـاب

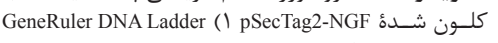

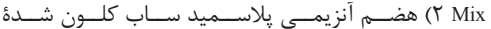

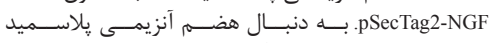

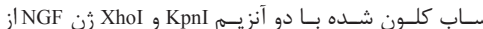

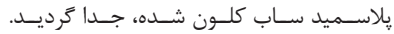

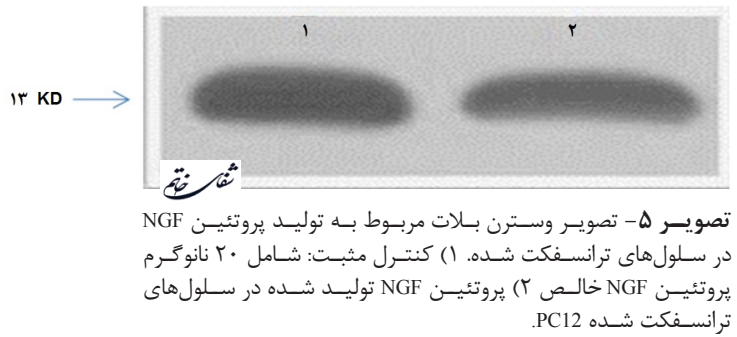

در اين تحقيق خندين عامل جهت افزايش كارايى ترانسفكت

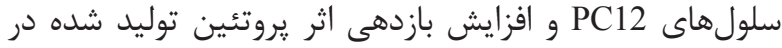
نظر كرفته شده است. استفاده از يلاسميد ترشحى

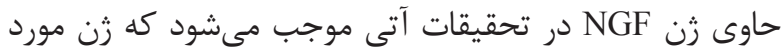

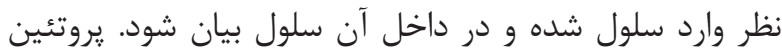

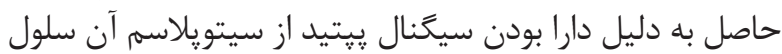

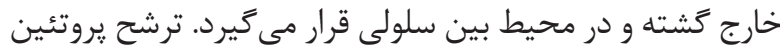

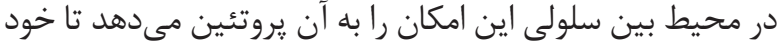

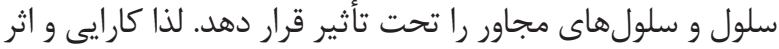

$$
\text { يروتئين حاصل بيشتر مى سول }
$$

به منظور كاهش ميزان مرك و مير سلولى در اثر ترانسفكت

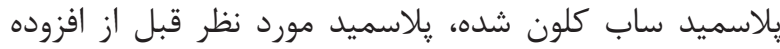

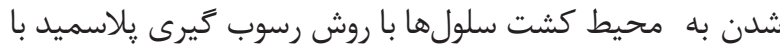

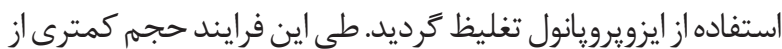

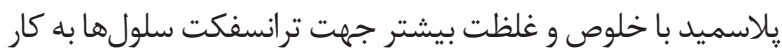
برده شد.

در مطالعه ما از روش لييوفكشن جهت ترانسفكت سلولها

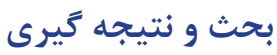

براى سالهاى متمادى درمان بسيارى از بيمارى هائ با استفاده

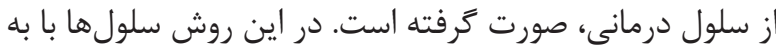

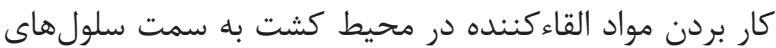

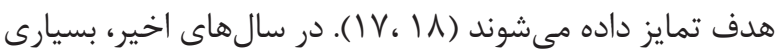

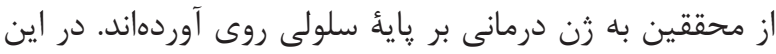

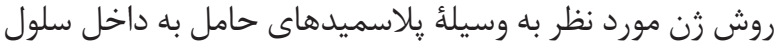

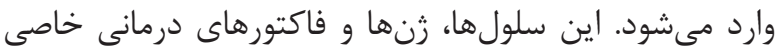

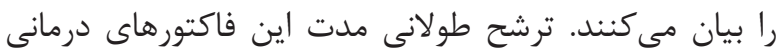



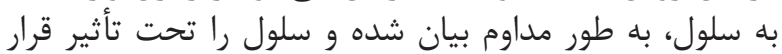

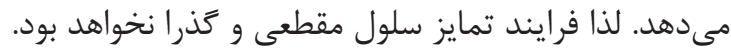

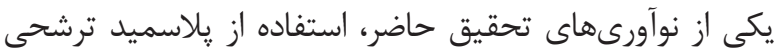

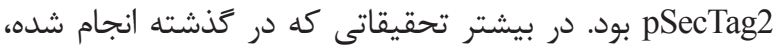

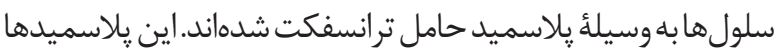

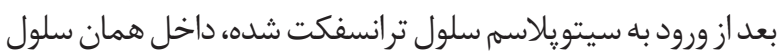
بيان شده و فقط همان سلول را تحت تأثير قرار مى دهندئد داخل همان. 


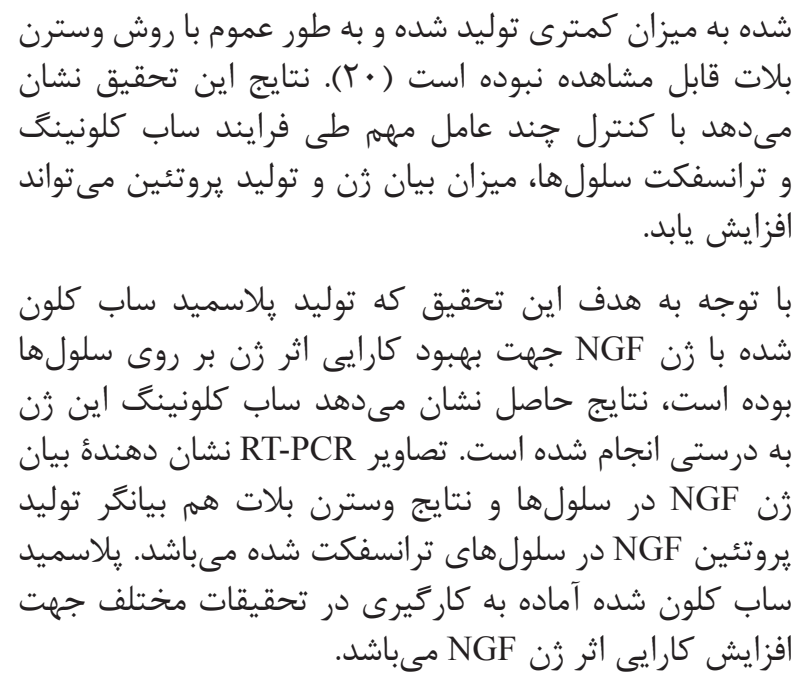

1. Kootstra NA, Verma IM. Gene therapy with viral vectors. Annu Rev Pharmacol Toxicol. 2003; 43: 413-39.

2. Biçeroğlu S, Memiş A. Gene therapy: applications in interventional radiology. Diagn Interv Radiol. 2005; 11: 113-8.

3. Park S, Kim HT, Yun S, Kim IS, Lee J, Lee IS, et al. Growth factor-expressing human neural progenitor cell grafts protect motor neurons but do not ameliorate motor performance and survival in ALS mice. Exp Mol Med. 2009; 41(7): 487-500.

4. Zhang ZH, Wang RZ, Wang RZ, Li GL, Wei JJ, Li ZJ, et al. Transplantation of neural stem cells modified by human neurotrophin-3 promotes functional recovery after transient focal cerebral ischemia in rats. Neurosci Lett. 2008; 444(3): 227-30.

5. Menuel S, Fontanay S, Clarot I, Duval RE, Diez L, Marsura A. Synthesis and complexation ability of a novel bis-(guanidinium)-tetrakis-(beta-cyclodextrin) dendrimeric tetrapod as a potential gene delivery (DNA and siRNA) system. Study of cellular siRNA transfection. Bioconjug Chem. 2008; 19(12): 2357-62.

6. Gheisari Y, Soleimani M, Azadmanesh K, Zeinali S. Multipotent mesenchymal stromal cells: optimization and comparison of five cationic polymer-based gene delivery methods. Cytotherapy. 2008; 10(8): 815-23.

7. Heese K, Low JW, Inoue N. Nerve growth factor, neural stem cells and Alzheimer's disease. Neurosignals. 2006-2007; 15(1): 1-12.

8. Lindsay RM. Role of neurotrophins and trk receptors
استفاده گرديد. ترانسفكت سلولها با واسطة لييوزوم نسبت

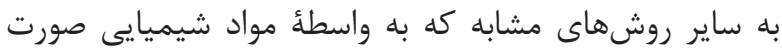

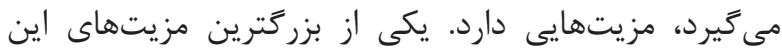

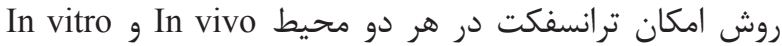



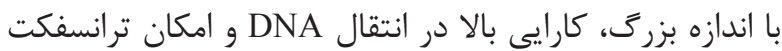

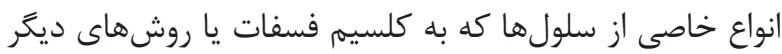

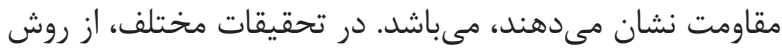

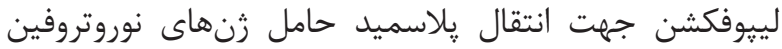
استفاده شده است (9) (19).

در اين تحقيق يروتئين توليد شده از زن ترانسفكت شده در

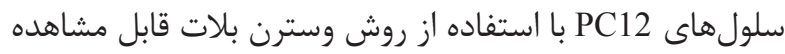

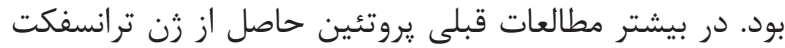

منابع

in the development and maintenance of sensory neurons: an overview. Philos Trans R Soc Lond B Biol Sci. 1996; 351(1338): 365-73.

9. Memberg SP, Hall AK. Proliferation, differentiation, and survival of rat sensory neuron precursors in vitro require specific trophic factors. Mol Cell Neurosci. 1995; 6(4): 323-35.

10. Davies AM. The role of neurotrophins in the developing nervous system. J Neurobiol. 1994; 25(11): 1334-48.

11. Koda M, Kamada T, Hashimoto M, Murakami M, Shirasawa H, Sakao S, et al. Adenovirus vector-mediated ex vivo gene transfer of brain derived neurotrophic factor to bone marrow stromal cells promotes axonal regeneration after transplantation in completely transected adult rat spinal cord. Eur Spine J. 2007; 16: 2206-14.

12. Ding J, Cheng Y, Gao S, Chen J. Effects of nerve growth factor and Noggin-modified bone marrow stromal cells on stroke in rats. J Neurosci Res. 2011; 89(2): 222-30.

13. Li LY, Li JT, Wu QY, Li J, Feng ZT, Liu S, et al. Transplantation of ngf-gene-modified bone marrow stromal cells into a rat model of alzheimer' disease. J Mol Neuroscience. 2007; 34(2): 157-63.

14. Freeman RS, Burch RL, Crowder RJ, Lomb DJ, Schoell MC, Straub JA, et al. NGF deprivation-induced gene expression: after ten years, where do we stand? Prog Brain Res. 2004; 146:111-26.

15. Madduri S, Papaloïzos M, Gander B. Synergistic 


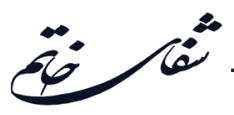

effect of GDNF and NGF on axonal branching and elongation in vitro. Neurosci Res. 2009; 65 (1): 88-97.

16. Cao X, Shoichet MS. Defining the concentration gradient of nerve growth factor for guided neurite outgrowth. Neuroscience. 2001; 103(3):831-40 .

17. Zhang H, Wang JZ, Sun HY, Zhang JN, Yang SY. The effects of GM1 and bFGF synergistically inducing adult rat bone marrow stromal cells to form neural progenitor cells and their differentiation. Chin J Traumatol. 2004; $7(1): 3-6$.

18. Naghdi M, Tiraihi T, Namin SA, Arabkheradmand J.
Transdifferentiation of bone marrow stromal cells into cholinergic neuronal phenotype: a potential source for cell therapy in spinal cord injury. Cytotherapy. 2009; 11(2):137-52 .

19. Hu Z, Ulfendahl M, Olivius NP. NGF stimulates extensive neurite outgrowth from implanted dorsal root ganglion neurons following transplantation into the adult rat inner ear. Neurobiol Dis. 2005; 18 (1): 184-192.

20. Triaca V, Tirassa P. Circulating NGF antibody alters the distribution of NG2 and CD56 positive cells in the brain of an animal model of inflammatory disorder. Arch Ital Biol. 2003; 141(2-3): 127-39. 